\begin{tabular}{|c|c|}
\hline 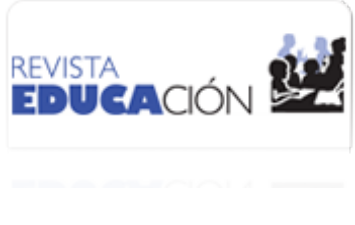 & $\begin{array}{l}\text { Revista Educación } \\
\text { ISSN: 0379-7082 } \\
\text { ISSN: } 2215-2644 \\
\text { revedu@gmail.com } \\
\text { Universidad de Costa Rica } \\
\text { Costa Rica }\end{array}$ \\
\hline
\end{tabular}

\title{
Currículum, ideología y capacidad crítica en la docencia universitaria
}

\author{
Casillas-Gutiérrez, Celerino \\ Currículum, ideología y capacidad crítica en la docencia universitaria \\ Revista Educación, vol. 43, núm. 1, 2019 \\ Universidad de Costa Rica, Costa Rica \\ Disponible en: http://www.redalyc.org/articulo.oa?id=44057415034 \\ DOI: https://doi.org/10.15517/revedu.v43i1.30728
}

Esta obra está bajo una Licencia Creative Commons Atribución-NoComercial-SinDerivar 3.0 Internacional. 


\title{
Currículum, ideología y capacidad crítica en la docencia universitaria
}

\author{
Celerino Casillas-Gutiérrez \\ Universidad Nacional Autónoma de México, México \\ casillas0302@yahoo.com.mx \\ (D) http://orcid.org/0000-0002-3410-4938
}

Curriculum, Ideology and Critical Skills in University Teaching

DOI: https://doi.org/10.15517/revedu.v43i1.30728

Redalyc: http://www.redalyc.org/articulo.oa?id=44057415034

Recepción: 10 Octubre 2017

Aprobación: 24 Diciembre 2017

\section{Resumen:}

En este trabajo se pone énfasis en la posibilidad de conformar la capacidad crítica del cuerpo docente universitario. Por ello, se considera la situación actual de la educación en el contexto de la globalización, neoliberalismo y desarrollo científico tecnológico y los fines que esta persigue bajo el discurso del enfoque educativo por competencias. A su vez se trata de develar los sentidos y significados que aparecen en el currículum tanto formal como oculto, la carga ideológica que se impregna en las instituciones de educación superior a través de la organización y distribución de los contenidos, saberes y conocimientos que son reproducidos por el profesorado. El objetivo de este trabajo es reconocer la práctica educativa y el papel de la ideología presente desde el currículum oculto y las posibilidades que ofrece la conformación de la capacidad crítica en la transformación individual y colectiva del personal docente universitario. En las conclusiones aparece la posibilidad de conformar una capacidad crítica desde su práctica; su subjetividad, sus experiencias personales, psicológicas, afectivas, socioculturales y políticas y su objetividad, de todo lo que le ofrece el mundo material, social, económico y político, además de reconocerse en y con el otro dentro del salón de clases con miras a lograr su emancipación y autonomía que le permitan actuar y transformar su mundo.

Palabras clave: Capacidad crítica, Práctica educativa, Currículo, Ideología.

\section{Abstract:}

This article emphasizes the possibility of developing critical skills among university faculty. It considers the current state of education within a context of globalization, neoliberalism and scientific technological development through an educational skillsbased focus. It also addresses understanding both the formal and hidden sense and meaning behind a curriculum, how it permeates higher learning institutions as a result of how its contents is organized, distributed and reproduced through the knowledge of the teaching faculty. The objective of this study is to acknowledge the use and role of this ideology within hidden curriculums and the advantages of developing critical skills on the individual and collective transformation of the university faculty. The conclusions pursue the possibility of developing the critical skills of the faculty through practice, subjectivity, personal, psychological, affective and political experience as well as its objectivity, which refers to the material, social, economic and political realms. It also encompasses acknowledging others within the classroom in order to attain emancipation and autonomy and, thus, transform the world.

KEYWORDs: Critical skills capacity, Educational practice, Curriculum, Ideology.

\section{INTRODUCCIÓN}

La educación dentro de una sociedad puede asumir dos roles; uno es que sirva a los intereses de las clases sociales y se le utilice como una forma de alienación al sujeto, y dos que, a través de ella, pueda convertirse en una herramienta de emancipación de mentes y transformación social.

En este ensayo se parte del supuesto que es posible la conformación de una capacidad crítica del cuerpo docente universitario desde su práctica. Para ello, cada docente tiene la consigna de develar todos aquellos marcos ideológicos que conforman sus experiencias de vida, de su práctica social y educativa a partir de los sentidos y significados culturales que le dan forma a su actuar y quehacer educativo. La reflexión y la crítica desde su subjetividad como sujeto histórico e indeterminado y la posibilidad de descifrar su entorno sociocultural, político, económico como parte de las relaciones de poder pueden generar en este los 
constructos necesarios para emanciparse y constituirse como un ser autónomo. Al lograrlo podrá tener una incidencia directa en el alumnado desde el salón de clases en la búsqueda continua de re-conocerse ambos como seres sociales, psicológicos, afectivos y políticos, donde pueda emerger la constante lucha por reflexionar y transformarse a ellos y al mundo mismo.

En el contexto de la globalización y el neoliberalismo, en los últimos años se ha alimentado la idea de que solamente produciendo seres tecnificados, con habilidades y destrezas (competentes), se podrá acceder a una forma de vida justa e igualitaria. La instauración del enfoque educativo por competencias en las instituciones educativas es muestra de cómo a través de la educación se puede configurar un tipo de ser humano nuevo.

Si bien es cierto que el currículum puede ser revisado según el tipo que se trate, formal, vivido u oculto, cada uno de ellos, favorece a determinadas prácticas educativas que emergen en la escuela en la relación docente y alumnado. Pero es a través del currículum ${ }^{[1]}$ oculto donde se legitiman los saberes y conocimientos para mantener la reproducción del sistema, dentro de las Instituciones de Educación Superior (IES), los docentes, estudiantes y demás actores educativos de manera consciente o inconsciente se convierten en cómplices de la legitimación de lo que el sistema capitalista demanda. Es en los planes y programas de estudio donde se organizan y deliberan qué tipo de conocimientos y qué forma de vida debe aprenderse en el salón de clases. El currículum oculto también se muestra con todos aquellos valores, normas, costumbres y experiencias de vida que no son legitimados pero que se introducen desde los marcos ideológicos que trae consigo tanto el docente como el estudiante.

Ante el develamiento de las luchas de poder, y la imposición de ideologías reproductivas, el docente puede desde su práctica emanciparse y transformarse a sí mismo y con la sociedad. Para ello, la reflexión, la crítica hacia su propia práctica y el cuestionamiento hacia su propia vida y hacia las condiciones socioculturales y políticas pueden generar en él la conformación de una capacidad crítica. El salón de clases entonces puede convertirse en un espacio que ayude a docente y a estudiante a reencontrarse y resignificarse.

La conformación de la capacidad crítica que posibilite la toma de conciencia de lo que se es con y para con su mundo. La reflexión y la crítica a sus realidades puede ser un eje importante en la consecución de un sujeto de resistencia y de lucha emancipatoria la cual permita la transformación. El reconocimiento de docente y estudiante en su individualidad y colectividad como seres inconclusos e históricos pueden ser elementos sustanciales para reflexionar, actuar y transformar su condición social e histórica dentro de la sociedad a la que pertenecen.

\section{ConteXto DEL MARCo EDUCATIVO ACTUAL}

Vivimos una época donde el rezago y los problemas educativos cada vez se acentúan en nuestra sociedad. Ante las condiciones sociales, políticas, económicas, etc., latentes y diferenciadas producto de la globalización y el neoliberalismo, la educación se convierte en una posibilidad emancipatoria en la condición del sujeto. Estamos ante un mundo incierto, donde todo es movimiento, llevamos una vida dinámica y líquida que se escurre con la inmediatez, y con ello un sujeto que se convierte en pasivo, inactivo, que nos deja sin posibilidades de crítica, de reflexión, de transformación (Bauman, 2008, 2009).

Las IES en nuestro país sean públicas o privadas tienen marcos referenciales e ideológicos desde la cual se construye el proceso educativo. En el caso de las universidades públicas todavía se recupera la función social, de tal forma, desde su misión, plantean una intencionalidad de la búsqueda de personas egresadas que favorezcan el servicio comunitario y el apoyo a los diversos sectores de la sociedad. No así, en la universidad privada, en esta, la función se ha desplazado a lo mercantil-empresarial, ubicando a la educación como una mercancía, como un negocio, lo que implica una lógica diferente en lo que se pretende para con sus egresados, una lógica que no está explícita, pero sí implícita en el proceso educativo.

Si bien es cierto hay que matizar las formas y contenidos de cómo las IES permean su condición de acumulación, legitimación y reproducción de conocimientos, en la gran mayoría de ellas, prevalece una 
ideología dominante, de reproducción, de alienación hacia el otro que solo sirven en gran medida a intereses de grupos particulares, son pocas las que aún siguen manteniendo, una ideología que favorecen el desarrollo y bienestar común.

Estas mismas universidades se enmiendan en un perfil que requiere para la sociedad (productividad, reproductividad y tecnicidad) y bajo esos esquemas se reproduce el discurso educativo el cual establece que quien accede a las universidades será una persona productiva, exitosa y con un puesto de trabajo que será bien remunerado, cayendo en falacias que atentan contra el sujeto. Si bien, estos planteamientos tienen eco y han funcionado desde la perspectiva de una sociedad posmoderna (Lipovestsky, 2003 Lyotard, 1998), sociedad que ha dejado de lado la reflexión, la crítica y la transformación del sujeto para convertirlo en un ser alienado y funcional. Beck (2002), señala "cuanto más moderna se hace una sociedad, tanto mayor conocimiento crea sobre sus fundamentos, estructuras, dinámicas y conflictos” (p. 175) y por ende mayores posibilidades de perfilar un tipo de persona acorde a los intereses económicos.

La inmediatez y la superficialidad de los actos humanos suele ser la preocupación en un contexto globalizador y neoliberal. El nuevo ser humano de estos tiempos se ha enfocado a un vacío existencial en la búsqueda de la aspiración material, son pocos, los que ante, estas implicaciones pueden pensarse y repensarse hacia un bienestar personal y común.

Muchas IES ponen en manos de su personal docente estas tareas de reproducción del sistema capitalistaneoliberal donde se privilegia el individualismo, la competitividad, el utilitarismo y la posición del individuo como objeto que obedece, acata, y se representa como una mercancía que puede ser desechada fácilmente. Sin embargo, algunas todavía privilegian el conocimiento reflexivo y crítico el cual permite que el sujeto tenga referentes de toda índole; culturales, sociales, políticos, económicos, teóricos, experienciales, que puedan sustentar una visión transformadora y emancipadora de la sociedad en pro de la justicia, democracia, y responsabilidad social, la Universidad Nacional Autónoma de México, la Universidad Autónoma Metropolitana, pueden ser ejemplos de lo antes dicho.

Bajo la premisa de una escuela que legitima y reproduce conocimientos, el papel del docente se convierte en un sujeto mecanizado y tecnificado, lo que, a su vez, lo vuelve una pieza clave para reproducir el sistema dominante, desde su práctica lo aterrizará vía contenidos, establecidos en los planes y programas de estudio, y lo concretizará en práctica educativa hegemónica ya sistematizada, es decir, desde el currículum formal.

Para ello, la institución implementará, reglas, normas, procedimientos, reglamentos y estatutos desde los cuales se dictaminará el sentido pedagógico y en tantas ocasiones las formas del actuar educativo. Dicho sea de paso, esta intentará cubrir una serie de requisitos burocráticos-administrativos y académicos que le son supervisados por organismos certificadores, acreditadores y por la propia Secretaria de Educación Pública. En estos, dará cuenta sobre el quién, el qué, el cómo y el para qué del proceso educativo dejando al docente como una figura que legitima el conocimiento y al cual se le demandará cumpla con su función social de formación de sujetos.

En algunas IES mexicanas, la preocupación inmediata del docente es estudiar sobre las asignaturas que imparten, ir a cursos, actualizarse, profesionalizarse, tener posgrados para luego desde sus trincheras (el salón de clases) reproduzcan el conocimiento adquirido y no cuestionarse sobre su práctica, sus formas de vida y sobre la autoconcientización de su ser. Todo esto marcado desde la inmediatez, desde lo fácil, desde lo comercial. El síndrome de la impaciencia los persigue por mantenerse dentro de las universidades. Según Bauman (2008):

En nuestros días, toda demora, dilación o espera se ha transformado en un estigma de inferioridad. EI drama de la jerarquía del poder se representa diariamente (con un cuerpo de secretarias cumpliendo el papel de directores de escena) en innumerables salas de espera en donde se pide a algunas personas (inferiores) que «tornen asiento» y continúen esperando hasta que otras (superiores) estén Iibres «para recibirlo a usted ahora» (p. 22).

EI emblema de privilegio (tal vez uno de los más poderosos factores de estratificación) es el acceso a los atajos, a los medios que permiten alcanzar la gratificación instantáneamente. La posición de cada uno en la 
escala jerárquica se mide por la capacidad (o la ineptitud) para reducir o hacer desaparecer por completo el espacio de tiempo que separa el deseo de su satisfacción. EI ascenso en la jerarquía social se mide por la creciente habilidad para obtener lo que uno quiere (sea lo que fuere eso que uno quiere) ahora, sin demora.

Otra de las plagas que está al lado nuestro es el neoliberalismo silencioso, el cual explora alternativas en las formas de pensamiento del docente alcanzando a separar cualquier capacidad crítica, lo encierra en su mundo, no le da posibilidades de reconocerse como sujeto, lo aprisiona, lo condiciona a un sujeto operador de procesos técnicos, lo moldea y le da el carácter de uso. Aunque ese pragmatismo generalmente lleva al ser humano aspiracional y material a la búsqueda del tener más que del ser.

El modelo neoliberal se encarga de que en las universidades a través de la formación de sus docentes se reproduzca y legitime su mantenimiento, bajo la concepción de que este es una pieza importante en la consecución de sus fines y garantiza en la simulación los intereses que demandan los grupos de poder. La reflexión del docente y la crítica es suprimida por el allanamiento de conocimientos tecnificados. Esta crítica en el docente debiera encarnarse, impregnarse como una forma de vida.

La crítica se ve como un fundamento de una reflexión indispensable en los procesos educativos. Así se entiende como aprendizaje reflexio: "el proceso de examinar internamente y explorar un asunto de importancia impulsado por una misma experiencia, que crea y esclarece un significado en términos de uno mismo, y que resulta en una perspectiva conceptual cambiante" (Boyd y Fales citados en Brookfield, 1989, p. 242) a lo que se puede agregar que esto tiene que ver con actividades intelectuales y afectivas en las cuales los individuos se comprometen a explorar sus experiencias para dirigirse a nuevas reflexiones y expresiones (Glazman, 2009).

El terreno intelectual y afectivo son dos premisas importantes para el reconocimiento del docente como ser histórico dentro de su sociedad y dentro de ese espacio institucional llamado salón de clases, con posibilidades de autoconcientización y autorreflexión sobre su práctica que le permitirá un intercambio de experiencias con sus estudiantes en la búsqueda de sentidos y sinsentido de las realidades ${ }^{[2]}$ que aqueja a ambos.

Es a través de la intelección crítica y analítica donde el docente puede recuperarse a sí mismo, replanteando su propia práctica y el papel que le corresponde como agente de cambio y transformación social. Aunque esto no podría ser posible sin el contacto con los otros, estos procesos de socialización del conocimiento con sus pares y con sus estudiantes, que pueden permitirle un andamiaje intelectual para darle sentido y significado a sus prácticas.

El docente como un ser humano psicológico, afectivo, tiende a manifestar sus estados de ánimo, ante sus propias acciones desprendidas de la vida cotidiana y de su práctica, el reconocimiento de esto, puede facilitarle el camino para considerarse como una persona no solo racional sino también emocional y con base en ello, reconozca desde ahí su historicidad, sus espacios y sus tiempos para discernir entre el acto mecánico y la reflexión crítica ante su realidad.

El desarrollo y conformación de una capacidad crítica ${ }^{[3]}$ del docente en su proceso formativo, que le permita mirar su mundo interno y externo puede ser un detonante en la apropiación de un mundo crítico y reflexivo ante sí mismo, con los demás y con su entorno. Las IES se convierten así en un espacio de relaciones de poder, provistas de herramientas tácitas y explícitas de control para con los docentes que tendrán que lidiar con los intereses institucionales, sociales, económicos y políticos de los que son presas. Aunque siempre habrá docentes que se resisten ante los embates de regulación y control que el propio sistema dominante impone.

\section{RELACIÓN CURRÍCULUM-IDEOLOGÍA-CAPACIDAD CRÍTICA}

Para el Estado, las instituciones educativas se han convertido en un bastión importante para desde ahí conformar un tipo de persona y, sociedad que convenga a intereses de clases y, grupos de poder. A través del currículum, se moldea al tipo de ciudadano que queremos ser, se deciden contenidos, métodos, estrategias, recursos con los que un docente debe enfrentar su práctica. 
La visualización desde un enfoque curricular crítico nos permite revisar el influjo del currículum dentro de la vida de las personas, así como el impacto, sus consecuencias y significados políticos y sociales que genera la práctica educativa, y la validación de un contexto natural del conocer, del hacer y del ser, como si no fuera dependiente de una construcción social e histórica. En ese sentido, se hace una apreciación crítica de reconocer los valores, la ideología y la práctica política que se esconde tras la práctica del currículum y ante ello, se genera un compromiso moral que intenta la emancipación política.

Es a través del currículum como se pueden seleccionar otros tantos contenidos culturales -ante los ya dados o naturalizados- como una forma de reconstruir el conocimiento de que disponen los grupos sociales, y por ende, mostrar un interés por las estrategias de enseñanza y aprendizaje que faciliten los procesos de reflexión, crítica, transformación, de participación democrática, de responsabilidad y solidaridad.

Ante la idea del currículum, los tipos, que han sido los reconocidos para poder comprender el proceso educativo y las prácticas que de ello se desprende son:

a) El currículum formal o explícito, el cual se entiende como la organización y planeación de las experiencias de enseñanza-aprendizaje de manera sistematizada, ordenada, controlada y su legitimación es racional-institucional. La formalidad está desde su fundamentación hasta la puesta en práctica de lo concreto, sostenida por una estructura académica, administrativa, legal y económica. También suele llamársele plan de estudios.

b) El currículum real o vivido representa todas aquellas experiencias, significados, formas de vida que constituyen las diferentes prácticas cotidianas de la persona que no son sistematizadas, pero cobran sentido en el momento que se recuperan dentro de la realidad del salón de clases en el día a día.

c) El currículum oculto alude a todos aquellos conocimientos, habilidades, actitudes, valores, prácticas, normas, costumbres, creencias, lenguaje, símbolos que se introyectan mediante el proceso de enseñanza y aprendizaje y en todas las interacciones cotidianas del docente y estudiante dentro del salón de clases, además, no son explicitados de manera intencional en los objetivos y metas educativas de la escuela, sino son encubiertas y latentes.

En este último tipo de currículum donde la ideología aparece y penetra en las prácticas cotidianas de los docentes. Apple (1990) alude al currículum escolar al decir: "No puede ser comprendido de un modo positivista. Necesita ser comprendido relacionalmente, con su significado que le es dado por las conexiones que tienen en las complicadas configuraciones de dominación y subordinación en la nación entera y en cada región particular o escolar" (p. 155). En ese sentido, es muy común encontrar en los planes y programas de estudio de las escuelas un contenido homogéneo que es dado como igual para todos sin respetar el contexto, la cultura, la región, la localidad de las y los estudiantes, y tampoco del docente.

El currículum escolar no puede visualizarse como un cuerpo de conocimientos neutro, sino como una producción social que legitima el conocimiento de la clase dominante. La escuela como principal agente de generación de conocimientos se convierte en una institución que sirve a intereses de un sistema capitalista, pero a su vez se genera al interior una lucha entre los grupos dominantes y los grupos subordinados que generan resistencia. "De alguna forma el currículum refleja el conflicto entre intereses dentro de una sociedad y los valores dominantes que rigen los procesos educativos” (Sacristán, 1998, p. 17).

En el currículum hay una intencionalidad que responde a intereses económicos y culturales por lo que no está explicitado de manera formal en los planes y programas de estudio, sino más bien encubierto y ambiguo, por lo que son pocos docentes que pueden develar sus verdaderos intereses. De esta forma, el currículum se convierte en un espacio de lucha ideológica, y una pugna entre los intereses de la clase dominante.

El sistema capitalista pone en manos del currículum su reproducción eficientista, utilitarista, mercantilista, a través de los planes y programas de estudio que son aceptados por las instituciones educativas, dado que el mismo sistema a través del Estado y la misma escuela legitiman estos procesos. Las diversas políticas educativas 
que giran en torno de un ser humano productivo y utilitario no son más que señales del claro predomino racionalista de los grupos de poder. Lungrend (citado por Sacristán, 1998) expone:

\begin{abstract}
los currículos son la expresión del equilibrio de intereses y fuerzas que gravitan sobre el sistema educativo en un momento dado, en tanto que a través de ellos se realizan los fines de la educación en la enseñanza escolarizada. Por lo cual, querer reducir los problemas relevantes de la enseñanza a la problemática técnica de instrumentar el currículum supone una reducción que desconsidera los conflictos de intereses que anidan en el mismo.

El currículum, en su contenido y en las formas a través de las que se nos presenta a los que se ha sedimentado dentro de un entramado cultural, político, social y escolar; está cargado, por lo tanto, de valores y supuestos que es preciso descifrar. Tarea a cumplir desde un nivel de análisis político social como desde el punto de vista de su "instrumentación más técnica”, descubriendo los mecanismos que operan en su desarrollo dentro de los marcos escolares (p. 17).
\end{abstract}

El currículum toma forma y sentido dentro del proceso educativo y es difícil desdeñar su objetivo implícito, político e ideológico. Las prácticas educativas cobran significado cuando estas son analizadas, interpretadas y resignificadas a través de la criticidad de la realidad que el docente vive en el día a día. A partir del currículum se regulan los procesos formativos, normativos, prescriptivos, de lo que debe ser el currículum, parece ser que desde la teoría se justifican y legitiman los intereses políticos e ideológicos de la clase dominante que son quienes verdaderamente deciden sobre el qué, el cómo y para qué de la educación.

Pansza (1997) advierte que "las visiones críticas del currículo toman conceptos que habían sido cautelosamente evadidos como el autoritarismo y el poder y declaran que el problema de la educación no es técnico sino político. Sin que por esto se niegue la posibilidad de trabajar científicamente el currículo" (p.13). Lo que está en juego dentro del currículum es la lucha entre los dominantes y los dominados, las relaciones de poder se ven manifestadas en los proyectos, las metas educativas, pero también, en los contenidos que se adhieren a una forma de pensar el mundo. Los valores, las normas, las costumbres, las creencias, la cultura forman parte del proceso educativo que son desplegados en formas particulares que reproducen un sistema hegemónico.

El currículum responde a un momento particular determinado: "La práctica, sin embargo, a la que se refiere el currículum es una realidad previa muy bien asentada a través de comportamientos didácticos, políticos, administrativos, económicos, etc., detrás de los que se encubren muchos supuestos, teorías parciales, esquemas de racionalidad, creencias, valores, etc. que condicionan la teorización sobre el currículum" (Sacristán, 1998, p.13). Por ello, desde la puesta en práctica del currículum se hace necesario el diseñar, implementar, planes y programas de estudio que hagan funcional al sistema productivo, y responda a sus propias necesidades, todo ello a partir de un diagnóstico de necesidades en la que se demandan ciertas prácticas profesionales las cuales requieren el mismo sistema.

Habrá que repensar la actuación profesional del profesorado en relación con el funcionamiento de la escuela y a las condiciones que se imponen, así como las pretensiones que este tiene para ella y la mirada como resuelve las diferentes problemáticas y los dilemas de los que toma conciencia. Es de suponer que puede que no sea suficiente que el docente convierta en un proceso consciente lo que ya hace de manera explícita. Más bien, será necesario que tome conciencia de sus propias limitaciones en su quehacer profesional, producto del allanamiento institucional y de las restricciones y deformaciones a que está sometido su pensamiento.

El currículum oculto se toca y trastoca dentro de las IES, y con ello las formas de vida dentro del aula, se entretejen y dan paso a las subjetividades de los actores, que en ocasiones se nulifican a partir de los discursos y mensajes que emanan desde sus propias concepciones de vida, pero también de las condicionantes sociales, políticas, económicas que de la sociedad se desprenden. "El currículum oculto se apoya en aquellos aspectos organizativos de la vida del aula que generalmente no son percibidos ni por los estudiantes ni por los profesores. Algunos elementos del currículum oculto están configurados por tres conceptos analíticos clave: multitudes, alabanza y poder" (Giroux, 1992, p. 75).

En esta apreciación del currículum oculto, aparecen las interconexiones con la propia ideología y las formas de enseñanza. Dentro de las escuelas no solo hay enseñanza de contenidos, sino también normas, valores, 
principios, que las y los estudiantes aprenden a partir de las diversas experiencias de la cual son objeto. La selección de contenidos, la organización y distribución del conocimiento es un proceso que se oculta en el terreno ideológico. No obstante, es este docente que en el ejercicio de su práctica consciente puede favorecer un cambio radical en la forma de replantear sus propios juicios y pensamientos que lo coloquen como un profesional que tiene la capacidad para resolver problemas y atender las necesidades reales de los estudiantes.

Lo que los estudiantes aprenden del contenido formalmente sancionado del currículum es mucho menos importante de lo que aprenden de los supuestos ideológicos encarnados en los tres sistemas comunicativos de la escuela: el sistema curricular, el sistema de estilos pedagógicos de controlar la clase, y el sistema evaluativo (Giroux, 1992, p. 72).

Los mensajes implícitos y ocultos recibidos a través del discurso institucional, del docente, del propio alumnado manifiestan las formas en cómo las relaciones de poder se entretejen y le dan sentido a las prácticas educativas que posteriormente serán reproducidas en la sociedad. La ideología ${ }^{[4]}$ se traza y se configura como un hecho consumado en las prácticas cotidianas del docente, tanto dentro como fuera del salón de clases, de ahí emergen múltiples concepciones de vida y de mundo, pero también desde ahí se posibilita la generación de conciencia y la resistencia por transformar la realidad individual y colectiva del sujeto.

La idea e imagen del profesorado se presenta cada estudiante como esa figura de autoridad, de conocimiento, que no puede ser debatido ni cuestionado. Esta acción ideológica introyectada al estudiantado desde los primeros años de vida, primero en casa, posteriormente en la escuela, en los niveles básicos; ahí se le enseñará a callar, a tener un orden, a disciplinarse, a repetir información.

Ese alumnado al llegar a las universidades reproducirá esa misma conducta con toda una carga ideológica, de tal forma que solo se limitará a reproducir lo que en un momento determinado aprendió. Lo mismo le sucederá al docente, su historia de vida personal, social, política, psicológica, afectiva, emocional saldrá a relucir cuando este frente a los estudiantes y por ende tomará el papel que le fue dado ideológicamente en las prácticas sociales; el de reproductor de esquemas, esto lo hará de forma consciente o inconsciente bajo la idea de actuar conforme a lo solicitado y lo ya determinado.

En ese sentido, es claro que las escuelas reproducen la realidad social enajenante y hegemónica a través del profesorado, planes y programas de estudio y de los materiales que les son dotados. El libro de texto puede ser un buen ejemplo de esto. La tendencia educativa del enfoque por competencias que se ha extendido en los últimos años por todo el orbe es muestra de una intencionalidad implícita de convertir a la persona en alguien productiva y tecnificada, aunque en el discurso normativo y académico se presente como la panacea para resolver las problemáticas educativas actuales.

Sin embargo, no se puede dejar de considerar que bien orientado a reforzar las prácticas educativas reflexionadas, analizadas, concientizadas de las personas, este mismo enfoque, puede desarrollar un pensamiento crítico que favorezca el desarrollo humano y no solo laboral. De esta manera, el acercamiento a las ideas desestructurantes de esquemas y paradigmas para el y la docente y el alumnado pueden generar realidades educativas que posibiliten el cambio individual y social.

El pensamiento crítico es aquella manera de pensar -acerca de cualquier tema, contenido, o problema- en la cual el pensador mejora la calidad de su pensamiento haciéndose cargo diestramente de las estructuras inherentes al pensamiento e imponiendo estándares intelectuales sobre ellos. En otras palabras, el pensamiento crítico se consigue a través de un proceso consciente de mejoramiento mediante la autocrítica dirigida a cómo está pensando uno (León, 2014, p. 165).

La educación se convierte en un dispositivo que configura un tipo de persona que la prepara para enfrentarse al mundo laboral, dotándolo de habilidades, técnicas, conocimientos, y actitudes que benefician el trabajo artesanal y productivo. Todos los niveles educativos son presa de estas formas institucionales que condiciona el acto educativo. Esta visión tan desalentadora, mecanicista y maquiavélica nos imposibilita y nos ata a mantenernos como seres determinados y alienados a las condiciones imperantes del propio sistema, valga la pena decir, que aún en estas circunstancias, también hay alternativas que posibilitan ver a las instituciones 
como espacios que permiten el acercamiento a la crítica y la reflexión por parte de docentes y estudiantes en su condición de seres históricos, inconclusos e inacabados.

Las IES juegan un papel importante en el desarrollo de la generación y conformación de un sujeto diferente, menos marginado intelectualmente, con más conciencia histórica, social, política, cultural, más reflexivo y crítico consigo mismo y con sus realidades. Las IES pueden convertirse en espacios de arena cultural y de formación política de los actores que participan en el acto educativo (McLaren, 1998).

Ante ello, la escuela también se convierte en un espacio donde el sujeto tiene la posibilidad de emanciparse del orden establecido, del sistema y grupo dominante. En ese terreno Giroux (1992) establece que "las escuelas son sitios políticos involucrados en la construcción y control del discurso, significados y subjetividades" ( $\mathrm{p}$. 72). De ahí entonces que la escuela no es neutral, se ejerce en ella una acción política.

Docente y estudiante desde el aula, desde ese espacio cerrado, pueden ser partícipes de formas y concepciones de vida alternativas a las que regula la sociedad. Es en este punto donde la capacidad crítica ${ }^{[5]}$ puede ser un detonante y una posibilidad de conformar a seres menos alienantes y transformadores de sí mismos y de las realidades que día a día pasan a formar parte de su cotidianidad. En el proceso educativo, tanto docente como estudiante en una relación dialéctica pueden generar encuentros y desencuentros que desestructuren su pensamiento y sus paradigmas que los empuje a ubicarse en otras realidades y a tomar decisiones que favorezcan su propia concientización.

La capacidad crítica es el resultado de procedimientos de oposición y cuestionamiento en consecuencia es abierta. Incluye tanto elementos de origen emotivo como de carácter racional, no descarta, una propuesta que recupera la importancia de los valores, el sentido subjetivo del aprendizaje y sus elementos políticos sustentados en aspectos ideológicos (Glazman, 2014, p. 2).

La capacidad crítica permite recuperar la subjetividad del sujeto, su memoria histórica, su vida social, psicológica, emocional, herramientas fundamentales para lograr una plena conciencia de su realidad, desde la reflexión y crítica que le permitirá objetivar los procesos sociales, económicos, políticos, de la sociedad a la que pertenezca. En el terreno educativo, dentro de las IES, es el docente quien, a partir de construir, deconstruir, reconstruir su práctica educativa tiene elementos sustanciales para conformar esta capacidad crítica en los estudiantes. Esto no es tarea fácil, pues para poder propiciarlo con el otro tendrá que empezar consigo mismo.

Un educador radical, tendría que identificar primero la ideología que da forma a su contenido y a su metodología. Podría entonces apropiarse de ciertos aspectos fundamentales de estos modelos, pero dentro de un marco de referencia teórico en el que la literatura sea tratada no solamente como técnica sino como un proceso constitutivo de la construcción de significados y de investigación crítica de las fuerzas que dan forma a las experiencias vividas (Giroux, 1992, p. 198).

En ese sentido, es claro que las escuelas también son espacios de reflexión y crítica social tanto para el docente como para el alumnado, la conformación de una capacidad crítica es clave para poder desmarañar los intereses ideológicos de algunos grupos sociales. La posible conformación de una capacidad crítica tanto del docente como del alumnado puede ser generada desde el propio salón de clases, reconociéndose el uno con el otro, como seres subjetivos, con historias de vida compartidas y seres objetivos que develan los atares e intereses permeados en los contextos sociales, políticos y económicos y que regulan su condición y su práctica social.

\section{LA PRÁCTICA DOCENTE ANTE LA CAPACIDAD CRÍTICA}

El ser humano es una posibilidad, no le basta haber nacido, tiene que forjarse un sentido; esta toma de conciencia, de inacabamiento es lo que justifica su condición de educabilidad y posibilita su autorreflexión, autocrítica, autotransformación. En lo educativo, el docente parte de lo que es, del reconocimiento de su propia historia de vida, psicológica, afectiva, social, política, elementos que le generen una mirada 
emancipadora, autónoma sobre su ser y que le permita identificar las relaciones de poder existentes en las relaciones con los otros.

Siguiendo a Freire (1997) el docente necesita entender que, en esta inconclusión del ser, suyo y del educando, se funda la educación como un proceso permanente que tiende hacia la apertura; “... la formación es un proceso de desarrollo individual tendiente a adquirir o perfeccionar capacidades. Capacidades de sentir, de actuar, de imaginar, de comprender, de aprender, de utilizar el cuerpo..." (Ferry, 1990, p. 52). El docente es un ser que se forma y deforma con base en sus experiencias y sus subjetividades, es algo más que surge del interior de él, pero en mediación con el mundo se transforma y se potencializa como un ser activo que busca resistencia ante su propia práctica.

Es indispensable ubicar al ser humano dentro de su tiempo y espacio histórico social, pues la sociedad occidental contemporánea que compartimos exige determinados conocimientos y valores -calidad, productividad, eficiencia, eficacia, individualismo, consumismo, vulnerabilidad- en la forma de proceder de sus miembros, lo que condiciona el proceso formativo tanto del docente como del alumnado. En este orden de ideas, enfrentamos un proceso formativo absurdo y contradictorio que bajo el cliché educativo solo alcanza para cubrir indicadores administrativos y capacitar en habilidades utilitarista que impactan en la práctica educativa, y por tanto en la práctica docente, cuyo valor y sentido se pierde o es confuso.

Dentro del aula, docente y estudiante se encuentran y acuerdan tácitamente una manera de convivir, pero no lo hacen desde la nada, ambos tienen una trayectoria formativa dentro del mundo educativo, social, político, económico, ideológico. El docente no es la misma persona después de cada curso, algo en su práctica se movió, otra cosa es si quiere verlo; el estudiante llega con una manera de serlo y desde ahí emprende el camino. Podemos tomar la elección de ignorar ambos elementos y seguir sin que pase nada, deseando que el tiempo se vaya para cumplir con el requisito de transmitir información; docente y estudiante no invertirán la mirada para centrarse en sí mismo, reduciendo la educación a un mero acto cuya expresión se agota y acota en una verificación instrumental.

En este contexto, resulta inútil hablar de una práctica docente, solo tenemos actos que se ejecutan sin sentido, van y vienen, sirvieron para ese instante sin ninguna profundidad; el docente sale avante como puede y como quiere, eso sí, cumple con el programa, la duda queda si está formando al estudiante. Hasta cierto punto estamos tentados a decir que se está llevando un proceso formativo, si partimos de la premisa de que la persona se forma en distintos contextos y a través de diversos agentes, pero esto no soluciona nada y se convierte en un cliché que sirva para justificar cualquier cosa. Por ejemplo, el docente puede defender su negligencia diciendo que el estudiante ya venía así, que su actuar dentro del aula es añejo, se remonta desde la educación básica pasando por la educación no formal e informal.

La práctica docente tiene una vocación epistemológico-antropológico-ético que abre o cierra la existencia humana; si el ser humano es un ser inacabado, necesita formarse y la educación es un medio, el docente con su quehacer establece en la cotidianidad las condiciones para la construcción del saber; formar es crear posibilidades de crítica, donde el educando pueda encontrarse, sentirse y pensarse desde su circunstancia dentro del horizonte educativo; reflexionar y mirar el mundo con otros ojos, moverse en distintas perspectivas, deslizar el sentido y develar los significados de su práctica estudiantil. Zemelman (2011) menciona:

Colocarse ante las circunstancias es la disposición y capacidad para desplegarse conforme a un sentido, un para qué, que
influye sobre la construcción de conceptos en torno a la realidad externa. Significa romper con los contenidos ceñidos a
los límites para dar cuenta de lo real como espacio de sujetos: pensar desde el momento que obliga a hablar también de sus
aperturas, lo que alude al movimiento de lo producido como siendo lo constituyente de este y que transformamos en el
ángulo para considerar el momento sin restringirnos a sus estructuras cerradas (p. 34).

El quehacer docente tiene un sentido claro: que el educando tenga la posibilidad de reflexionar sobre sí mismo y a partir de esa reflexión re-conocerse; es decir, el docente emprende un trabajo con la persona que tiene al frente, crea condiciones las cuales permiten ubicar al estudiante en su nivel formativo, ver el trayecto 
recorrido para seguir o cambiar de rumbo, incluso quedarse en ese nivel es una opción siempre y cuando sea el educando quien lo decida, pues también él puede ejercer un poder consciente o inconsciente en contra del docente ante el proceso educativo.

En todo caso, le hace saber que “... aquel que se forma emprende y prosigue a todo lo largo de su carrera un trabajo sobre sí mismo, en función de la singularidad de las situaciones por las que atraviesa...” (Ferry, 1990, p. 77). Es tácito, el docente tiene una trayectoria formativa que compartirá con su educando, lo demás está en manos de este último. Siendo así, tenemos una consigna que ningún formador puede ignorar, él docente tiene que darse cuenta de su proceso formativo, tomar conciencia de su ser y de su mundo, no puede enseñar al educando si no tiene conciencia sobre sí mismo.

Para generar o desarrollar una capacidad crítica en el docente se requiere de una continua conciencia de la práctica docente y de su actuar como ser humano, es inevitable el compromiso y la responsabilidad que se acepta al ubicarse frente a un grupo. Los rostros que escuchan y miran tienen el deseo, la expectativa y la confianza de que al final del día dejarán de ser los mismos, podrán tener otros elementos para interpretar su realidad personal, familiar y social; y con ello, podrán construir un proyecto de acción a la altura de sus circunstancias y a sus propias posibilidades que involucra tanto continuar con su formación, como buscar las alternativas para estar en forma (Ferry, 1990).

La práctica docente es un movimiento que busca que el educando pase del apoyo al autoapoyo; dar contenidos decanta un horizonte educativo que cierra posibilidades formativas, en este escenario educativo no se puede esperar la construcción de saber, la conciencia se duerme y se acostumbra a pensar desde ningún referente; el educando se diluye, no hay posicionamiento dentro del aula como persona, ni como sujeto histórico, por eso busca la respuesta fuera de sí. Nada más ilusorio. El docente forma al educando en la medida en que le enseña a encontrarse dentro de sí, levantar los párpados y tener claridad de su circunstancia.

Un educando se está formando cuando la tarea del docente busca generar en él autonomía y sacarlos de su heteronomía. "EI maestro educa para la autonomía, y debe saber guiar al educando de la heteronomía a la autonomía, pues esta no se consigue de la noche a la mañana, sino a través de un proceso” (Rojas, 2010, p. 255). La práctica docente cumple su sentido cuando encamina al docente y estudiante en su propia constitución como sujetos históricos y estos comprenden que el trayecto de la formación solo puede ser vivido por aquel que se forma; el docente tendría que darse esa posibilidad hacía sí mismo y hacía el estudiante.

El camino no es fácil, que el personal docente recupere sus vivencias, sus formas de vida y le encuentre sentido a sus realidades, es un común denominador para encaminarse hacia la constitución de una conciencia que le permita criticar su propio quehacer y su entorno social, político, económico, del que forma parte.

\section{EL MARCO IDEOLÓGICO, PREMISA PARA EL ACTUAR DOCENTE}

El cuerpo docente dentro de su práctica trae consigo referentes ideológicos desde los cuales ejecuta el acto educativo y permea el proceso enseñanza-aprendizaje dentro del aula. La carga ideológica presente entre docente y estudiante condiciona una y otra vez el proceso educativo, generando relaciones de poder. McLaren (1998) es claro en este sentido el docente "debe descubrir los intereses ideológicos ocultos que subyacen en sus propias prácticas pedagógicas y su habilidad para enseñar y aprender con otros" (p. 280). Es un ser inacabado con posibilidades de transformarse ante el reconocimiento de que es también un ser alienado y que dentro de sus prácticas se esconden intereses que privilegian a los grupos dominantes. Por otro parte, Freire (2010) comenta respecto al docente

en primer lugar es preciso que el docente esté por lo menos inclinado a cambiar. En segundo lugar, el docente debe tener claro cuál es su posición política. La educación es una práctica política, y el docente, como cualquier otro ciudadano, debe hacer su elección. En tercer lugar, es preciso que el docente empiece a construir su coherencia, que disminuya la distancia entre su discurso y su acción...la primera pelea que un docente progresista debe dar es consigo mismo. Ese es el comienzo del cambio (p. 60). 
El profesorado debe estar claro hacia dónde inclinar su práctica, cómo favorecer una relación dialéctica con su entorno social, económico, político y cómo transformarse en pro de favorecer una visión de mundo distinta. Hablar de práctica educativa no solo es remitirnos al quehacer dentro del salón de clases, aunque es un espacio importante en la vida del docente y estudiante sino que esta práctica trasciende el aula y la propia escuela, es un práctica que tiene un sentido, acción política y una finalidad del para qué educar, para lo cual se vale del salón de clases y de la realidad totalizadora del docente y estudiante.

Un docente concientizado tiene más probabilidades de verse a sí mismo y entender su realidad de manera diferente y, por tanto, de modificar su práctica para efectos de resistirse de manera política y social ante los embates de los discursos emanados para reproducir el sistema de dominación.

El marco ideológico puede constituirse en un elemento central para que el docente actúe de manera diferente en su práctica dentro del salón de clases. Reconocer desde su posicionamiento cuál es la intencionalidad de su ejercicio académico y cómo sus pensamientos y sus paradigmas tiene influencia en el desarrollo formativo y profesional y hacía con el desarrollo de la capacidad crítica del estudiante puede generar opciones para la transformación individual y social del sujeto. Cualquier docente no actúa en el vacío, actúa con base en su ideología que puede externarla ante los otros, de manera implícita o explícita, pero que es esta, la que le da sentido a su condición como docente.

El mismo McLaren (1998) comenta al respecto que la práctica pedagógica es "aquella práctica que exige un compromiso con la trasformación social en solidaridad con los grupos subordinados y marginados, lo que por necesidad implica una opción preferencial por el pobre y la eliminación de las condiciones que permiten el sufrimiento humano" (p. 198). De ahí la importancia de cuestionar constantemente la práctica educativa porque si el docente y estudiante no se interrogan, no se descubrirá el carácter ideológico, reforzador de intereses ajenos y hasta contrarios a los sujetos que intervienen en el proceso enseñanza-aprendizaje. La pregunta en el desarrollo de la capacidad crítica tanto del docente como del estudiante puede ser una estrategia que conforme miradas de resistencia y de prácticas concretas de transformación.

Las vivencias y subjetividades de ambos y la configuración de su entorno social, económico y político forman parte de su quehacer educativo cotidiano.

La ideología crítica se centra en esta instancia alrededor de un análisis crítico de las fuerzas subjetivas y objetivas de dominación, y al mismo tiempo revela el potencial transformador de los modos alternativos del discurso y de las relaciones sociales basadas en los intereses emancipatorios. (Giroux, 1992, p. 185).

Recuperar la subjetividad del docente y del alumnado permite en el proceso de socialización del conocimiento conocer de fondo quiénes son y para qué son y cómo entre ambos pueden generar conciencia política y social.

El docente tiene con el educando una gran responsabilidad, pues es quien al convivir con este tendrá que desafiarlo para que participe como persona de su propia formación y de un actuar consciente ante la sociedad. Eso distancia dos actitudes dentro de la práctica docente: ceder ante las tentaciones de la instrucción de contenidos y la capacitación de habilidades o bien trabajar por la conformación de una capacidad crítica. Ambas posibilidades se nutren de uno y otro siempre. La gran tarea es darse cuenta de manera analítica, critica y reflexiva que sucede con su entorno y con el mundo y cómo pueden incidir en la transformación de este, para el beneficio social colectivo.

Los estudios que realizaron Sorbes y Torres (2013) sobre las percepciones que tenían un grupo de docentes universitarios colombianos sobre el pensamiento crítico y su aplicación en la Enseñanza de las Ciencias pueden ser ejemplos de que es posible que un docente desarrollo un pensamiento propio y concientizado. Se tomaron en este estudio tres categorías: concepciones de pensamiento crítico en docentes en formación, pensamiento crítico y enseñanza de las ciencias y contribuciones del pensamiento crítico y escenarios.

Los resultados arrojan que el personal docente reconoce la importancia del pensamiento crítico en los procesos académicos, pero difícilmente el mismo escenario educativo se fomenta este tipo de pensamiento. 
A su vez, cada participante atribuye a este pensamiento características de análisis, cuestionamiento, toma de decisiones y reflexión propios para su práctica educativa. Los autores concluyen que el estudio puede ser un fundamento que pueda promover estrategias didácticas que contribuyan al desarrollo de este pensamiento en la enseñanza de las ciencias.

De esto se puede deducir, que el profesorado tiene que asumir esta elección, primero siendo consciente de ella, y posteriormente siendo congruente entre lo que piensa, dice, hace y siente, develando el significado ideológico de todos los procesos del que forma parte, y que se entretejen en la vida social, económica, política y educativa del cual forma parte. Dentro del aula no puede permitirse exigir al estudiante que reflexione sobre su actuar y su condición como sujeto de aprendizaje, si el docente no tiene claro hacia dónde va, ni quiénes son sus interlocutores, si ni siquiera se ha preguntado, qué es lo que busca y desea, y para qué enseña.

Si el docente exige en el educando, desde un marco ideológico distinto dentro del proceso formativo; entiende que los contenidos y las habilidades son recursos que el estudiante debe aprender como medios para entablar un diálogo con el saber. Si contenido y habilidad se confunden con el fin educativo quizá solo esté en condiciones de exigir al estudiante su perfeccionamiento en una tarea. "No hay formación cuando el aprendizaje de un oficio no supera el pragmatismo que se contenta con transmitir recetas, ni cuando se sujeta a una praxeología que fija las reglas de acción en función de una norma de eficacia más o menos a corto plazo" (Ferry, 1990, p. 83). Enseñanza y aprendizaje no se reducen ni se sustituyen con aprender a aprender y aprender a hacer, el proceso es un poco más complejo, las diferencias pueden verse en las trayectorias formativas que se dibujan según se partan de alguna de ellas.

El proceso formativo que deviene en el docente y estudiante no es un instante que soluciona un problema, sino la constitución de un pensamiento y capacidad crítica que puede adelantarse a los problemas; la diferencia emerge si el docente puede crear un lugar que permita pensar y pensarse desde otra circunstancia dentro y fuera del aula, esto es, si se tiene la posibilidad de que la persona construya un lugar para completarse y reconfigurarse dándole un sentido y una significación a su actuar en el mundo.

Un acto formativo inicia cuando docente y educando se posicionan uno frente al otro para compartir un espacio desde donde se desarrollarán sus respectivas prácticas compartiendo sus experiencias, sus valores, sus emociones, sus formas de vida y sus realidades semejantes.

¿Cuál es el problema? Reside en que a veces las personas individualmente y como colectivos no desarrollan la conciencia de construcción porque no reconocen espacios posibles de construirse [...] Lo que busco señalar es que sin el reconocimiento del espacio es difícil que se desarrolle conciencia de construcción; aunque el mero hecho de tener consciencia del espacio, por sí mismo no resuelva el problema de la construcción, requiere que la persona tenga conciencia de que ella construye desde ese espacio (Zemelman, 2006, p. 53).

El escenario formativo es un espacio que tiene esa posibilidad de reconstruirse y construir desde los contenidos y las habilidades, como elementos de un proceso que ya fue abierto de antemano por el docente y el alumnado y que son cubiertos por la ideología que se impregna en su condición de ser. Solo desde el espacio común y consciente de su actuar y pensar, los contenidos y las habilidades de aprendizaje pueden ofrecerse al educando, solo desde este espacio el docente puede ordenar los temas y las estrategias; es cuando las prácticas educativas adquieren sentido, de otra manera asistimos a una coincidencia educativa.

Las IES pueden estar llenas de coincidencias. Docente y educando se desconocen, son extranjeros en el destino si es que lo hay; sus trayectorias formativas corren en paralelo, a veces chocan, otras se rozan, pero no se entretejen para hilvanar una misma ruta: asistimos a desencuentros formativos. Este dilema educativo es fácil de rastrear, tiene su historia en una práctica docente que solo se dedicó a planear y operar situaciones de enseñanza-aprendizaje y olvidó construir condiciones de producción y reflexión de saberes, así como de la conformación en estos actores de la capacidad crítica. Este hueco formativo es bastante severo porque el estudiante

... necesita apropiarse del entendimiento del contenido para que la verdadera relación de comunicación entre él, como alumno, y yo, como profesor, se establezca [...] Enseñar y aprender tienen que ver con el esfuerzo metódicamente crítico del 
profesor por desvelar la comprensión de algo y con el empeño igualmente crítico del alumno de ir entrando como sujeto en aprendizaje, en el proceso de desvelamiento que el profesor o profesora debe desatar (Freire, 1997, pp. 113-114).

Dentro de la práctica, el y la docente acondiciona el escenario formativo como réplica o emulación de contextos laborales que permitan perfilar competencias y usar herramientas derivadas de la información vertida en libros y manuales. En sentido estricto no hay acto formativo. El educando no logra entender su lugar dentro de su proceso formativo, y sin ese reconocimiento, no hay manera de sacarlo de una actitud pasiva o activa de exigir conocimiento en detrimento de convertirse en conocedor. "Es decir, no se trata de abrumar con todas las complejidades que están detrás de la construcción del conocimiento, pero sí se trata de darle una perspectiva de cómo ese conocimiento fue construido, porque quizá esa sea una enseñanza más permanente que el propio conocimiento que se transmite" (Zemelman, 2006, p. 123).

Construir, deconstruir y reconstruir el conocimiento es la apuesta para que el docente encuentre el sentido de su quehacer, y a su vez, se vea reflejado a sí mismo como una persona de contradicciones, de encuentros y desencuentros con sus propios pensamientos y significados que le permitan concientizarse de lo qué es y quiere ser, de lo qué ha sido y de lo que será. En ello, va el cambio de paradigma y de representaciones en el cual ha vivido en su práctica y que puede modificar si es capaz de concientizarse de manera política y social recuperando su historicidad dentro del contexto que le toca ubicarse.

La posibilidad de aprendizaje de un contenido descansa en la apertura del pensamiento reflexivo, crítico, tanto del docente como del alumnado. Un contenido que no se discute se solidifica en los esquemas cognitivos del educando, es una paradoja educativa, al ofrecerse una continuidad entre las IES y el campo laboral se crea la ilusión de que el conocimiento ya se aprendió.

El proceso formativo se vuelve un suspiro, replicar y contrastar es la premisa que justifica los niveles de ejercicio docente y los alcances de una práctica docente que no encuentra más expresión que demandar cursos de capacitación, estrategias de aprendizaje, recursos didácticos, control de grupo, modalidades de atención, entre otras. La comodidad se instala en la práctica formativa, y también en la estudiantil, cada uno da y recibe lo preciso, sin más ni menos; con la sensación de que la sola presencia ya ha cumplido la tarea de formarse.

... la educación o la acción cultural para la libertad es la autentificación del conocimiento mediante la cual los educandos y los educadores en tanto <<conciencia >> o en tanto seres plenos de <<intención >> se unen a la búsqueda de nuevos conocimientos como consecuencia de la aprehensión del conocimiento existente. Más aún, podemos identificar y evaluar lo que aún se desconoce. Si esto no fuese así, es decir, si el tipo de conciencia que reconoce el conocimiento existente no pudiese continuar buscando conocimientos nuevos, no habría forma de explicar los conocimientos actuales (Freire, 1990, p. 124).

El conocimiento no ha llegado a un límite, lo que sucede es que se dejó de formar estudiantes que conocen; el docente se perdió cuando se sustituyó educar por formar y se ciñó a los intereses de la clase dominante. El docente se desencantó de su práctica cuando aceptó su lugar en el mundo educativo como recurso, se perdió la tradición y la trayectoria docente cuando se le comparó con un capacitador del aprendizaje y se le dio la tarea de instrumentar el proceso educativo.

Entonces no le interesó otra cosa que cumplir, finiquitar su estancia dentro de los diversos escenarios formativos, solo la exigencia era mantenerse actualizado, tener información actual de la disciplina que imparte y el manejo de grupo. Lejos quedó esa advertencia freireana: "Saber que enseñar no es transferir conocimiento, sino crear las posibilidades para su propia producción o construcción” (Freire, 1997, p. 47).

El docente espera que alguien le responda cómo enseñar o diseñar experiencias de aprendizaje, se ha convertido en un aplicador de la enseñanza, por eso cuando la realidad estudiantil no cuadra con su esquema, el acto educativo se trivializa y solo se hace que los días se conviertan en una espera angustiante. La didáctica sale al quite como paliativo de un desgaste educativo que pronto mostrará sus dientes y garras en la trayectoria formativa del educando.

El lugar común que se perdió se rencuentra en ruinas, se contempla como un vestigio que no activa la memoria de una práctica docente y estudiantil que dirija los ojos hacia el futuro; lo que importa es el presente, 
sacar el día, cumplir los objetivos de aprendizaje como si eso fuera evidencia suficiente para afirmar que se ha contribuido con la formación de los profesionales que demanda la sociedad.

Los contenidos y las habilidades son el punto de partida más no de llegada del proceso formativo, darse cuenta del lugar donde uno se encuentra es la posibilidad para proyectarse hacia la apertura de sentido formativo y la posibilidad de reconocerse con el otro, empezando consigo mismo. La sociedad del conocimiento es un giro discursivo no solo a nivel nacional sino global que emana de los Organismos Internacionales (Organización para la Cooperación y Desarrollo Económico, Banco Mundial y Organización de las Naciones Unidas para la Educación, la Ciencia y la Cultura) y que trata de convencer que ya no hay más por conocer y que basta estirar la mano para elevar el capital cultural; hablar se equipara con pensar, poseer información es una etiqueta que simula que se sabe porque se tiene dominio del tema, aunque se ignore su marco cognoscitivo. En este contexto, el docente aparenta que domina el tema específico de tal o cual área, lo repite, lo expone, realiza actividades y califica si sus educandos pueden tener similar manejo de contenidos y habilidades.

... la función del conocimiento es detectar nudos desde los que pueda intervenirse para potenciar lo dado en la dirección de sentido que se busca construir. En conclusión, se establece un vínculo entre el acto de pensar y el de asumirse como sujeto, entre conocer y auto-conocimiento, que es lo que marca la singularidad de convertir a la conciencia histórica en premisa desde donde organizar el pensamiento (Zemelman, 2011, p. 47).

Si enseñar es la construcción de procesos cognoscitivos en el educando, la empresa del docente debe cambiar de rumbo. Puede seguir interesado en que sus estudiantes encuentren una oportunidad dentro del mundo laboral, pero esta oportunidad tiene que construirse a partir de que el educando se posicione como una persona que es consciente de su entorno político, social, económico, y de su propia vida. Esto se logra si el docente forma una actitud epistémica en el estudiante, con la cual este no solo se conforme con lo aprendido, sino que vaya más allá, que el contenido y la habilidad sean la posibilidad para construir una capacidad crítica.

Entonces, docente y estudiante hacen un alto en su camino, y desde un lugar común aprecian el panorama que está por delante; la tarea se ha cumplido, el docente sabe que su estudiante ha dejado de aprender, la trayectoria formativa que ha recorrido lo ha puesto delante del objeto de estudio. No hay más mediaciones, el docente presencia que su estudiante puede dialogar directamente con el conocimiento, dándose cuenta de que, al final quizá este“... sea un ignorante desde los puntos de vista de las calificaciones o de las evaluaciones escolares pero es un individuo que ha desarrollado una capacidad creativa para ubicarse en su momento construyendo su propia relación de conocimiento" (Zemelman, 2006, p. 84). Eso lo distinguirá de aquel que ha perfeccionado su know how cuando las posibilidades del presente potencial se abran y se expanda la realidad conocida.

\section{LA CONFORMACIÓN DE LA CAPACIDAD CRÍTICA EN EL DOCENTE DESDE SU PRÁCTICA}

Las condiciones actuales de la práctica educativa no pueden aportar elementos para solucionar los inconvenientes en los procesos de reflexión y crítica de la mayoría de los docentes y estudiantes de la IES, con ese perfil no puede haber propuestas para un presente educativo que se escurre entre los escenarios formativos. Los factores son muchos, pero dentro del horizonte educativo, la práctica docente se abre un espacio para potencializar los procesos formativos de los educandos. "Como seres conscientes, los hombres están no solo en el mundo sino con el mundo. Solo los hombres, en tanto seres <<abiertos〉>, son capaces de llevar a cabo la compleja operación de transformar el mundo con su acción y simultáneamente captar y expresar la realidad del mundo en su lenguaje creativo" (Freire, 1990, p. 85).

El docente puede redefinir el rumbo de un sistema y enfoque educativo que está pensado para ser eficiente y eficaz, sin la necesidad de quejarse o confrontarse; aceptar la condición en la que le ha tocado cultivar su práctica docente es un primer momento, después tiene que comprometerse para transformarse y enriquecer 
la realidad educativa. Abrir un diálogo con el mundo circundante es un principio de claridad que permite entender que el presente no está acabado, sino que es una apertura desde donde se puede construir un futuro. En palabras de Freire (1990):

Si no superaran su adherencia al mundo y emergieran de ella en tanto consciencia constituida en la <<admiración $>>$ del mundo como su objeto, los hombres serían simplemente seres determinados, y sería imposible pensar en términos de su liberación. Solo los seres que pueden reflexionar acerca del hecho de que están determinados son capaces de liberarse. Su reflexión no conduce únicamente a una conciencia vaga y no comprometida sino al despliegue de una acción profundamente transformadora sobre la realidad determinante (p. 86).

La reflexión del docente sobre su práctica y la crítica sobre sí mismo y hacía con su mundo es una necesidad si se tiene en la mira la conformación de un sujeto autónomo. Es necesario que el docente avance hacia un nuevo orden que establezca una ruta adecuada para la conformación de una capacidad crítica. "La reflexión, componente esencial de la crítica, va de la mano de la adquisición de una postura clara; a su vez la claridad de la propia postura facilita al estudiante (y docente) entender posturas y supuestos de los otros" (Glazman, 2009, p. 242).

Las experiencias que recoge Betancourth (2015), con un grupo de docentes de Psicología de la Universidad de Nariño en Colombia para desarrollar el pensamiento crítico dan muestra de que existen posibilidades para fomentar la reflexión y la acción desde el terreno de la concientización del sujeto ante su práctica. En su estudio se tomaron como categorías de acción para el desarrollo de habilidades de pensamiento crítico el posicionamiento del docente ante su práctica: respeto por la posición del otro, construcción de acuerdos, empatía intelectual, coherencia y argumentación. Los hallazgos encontrados sugieren que se hace presente el pensamiento crítico del docente cuando se generan las estrategias adecuadas dentro del salón de clases, como la investigación, la empatía intelectual con las y los estudiantes y con los materiales y hacen uso de estas de manera tal que se puedan dinamizar de tres formas: incorporándolas a un contexto especial como un proyecto, cambiando su estructura o incorporando material didáctico a las mismas.

Sin duda, permitirle un espacio de diálogo al docente dentro de las IES es imprescindible porque no se puede ver en dónde se está posicionado si no hay un interlocutor. Compartir experiencias de la práctica docente es un catalizador que permite re-conocerse y encontrarse en el discurso del otro, los ojos no solo miran la realidad circundante sino que se miran como un acto de autoconciencia. Emerger como observador de segundo orden y darse a la tarea de preguntarse por qué y cómo se ha llevado la propia práctica docente; devela su actuar cotidiano frente al estudiante y se da cuenta de que puede elegir: quedarse así o moverse.

Digamos lo siguiente: La relación de conocimiento es la capacidad que tiene cada individuo de colocarse en su mundo, Pero ¿qué significa colocarse en su mundo?

Significa no explicarlo, sino interpretarlo, reconocerlo. Pues la primera exigencia de la colocación es ponerse en su mundo sin la mediación precipitada de reducir esa relación a una explicación (Zemelman, 2006, p. 82).

No puede haber cambio en el docente si no se sabe la posición que se tiene, se puede cuestionar lo que se está haciendo, pero eso no sirve si no se tiene conciencia desde dónde se hace tal cuestionamiento. Eso puede explicar el fracaso de los cursos o capacitaciones docentes que menguan la práctica docente en lugar de enriquecerla porque no son capaces de mostrar el para qué de la enseñanza.

El mundo educativo se aglomera, se atiborra, se desfigura, porque no se tiene un punto de referencia; el docente no reflexiona, no crítica, solo actúa y siente de manera superficial; desde esta perspectiva qué orden puede encontrar en su práctica. Si deseamos remover la apatía docente, tenemos que mostrarle el mundo educativo, no el que se quiere imponer sino el que se vive cotidianamente, recuperar su propia historia de vida con el agregado de develar la ideología presente en los procesos sociales, económicos, políticos y económicos. Las reservas ante el posicionamiento reflexivo y crítico pueden ser justificadas, el punto es si se tiene la actitud para dialogar. 
Los docentes reflexionan en relación con las implicaciones éticas y morales y acerca de las consecuencias de las prácticas educativas sobre los estudiantes. Estos docentes extienden sus consideraciones hasta problemas más allá del salón de clases para incluir ideales democráticos. Al reconocer que las prácticas del salón de clases y de la escuela no pueden separarse de las realidades políticas y sociales en un contexto determinado, los docentes reflexivos se esfuerzan de manera crítica por estar completamente conscientes del conjunto de consecuencias derivadas de sus acciones.

Pocos docentes pasan un día sin enfrentar dilemas de tipo ético. Inclusive la evaluación rutinaria del trabajo de los estudiantes implica, de cierta forma, una decisión ética ya que la falta de oportunidad de aprender, así como el impacto sobre el concepto de sí mismo son consideraciones que siempre están presentes. Aunque dentro de la gama de descripciones de la práctica reflexiva algunos incorporan una postura crítica, muchos no lo hacen (Villalobos y Cabrera, 2009, pp. 152-154)

En otras palabras, la práctica docente también es la expresión de algo que no se está trabajando bien en las IES, hay que partir de eso, de lo contrario no estamos abiertos para tener un interlocutor; cuando el docente se sitúa dentro del mundo educativo, este emerge decantando las posibilidades formativas que se tiene al alcance, y eso es conveniente para cada actor de la Institución Educativa, es decir, con el advenimiento de la práctica docente, las IES tienen la oportunidad de mirarse, y por qué no, la opción de aceptarse.

En consecuencia, el acto de pensar como tal refleja una postura de autonomía del sujeto que se traduce en definir un "ante" que lo distancie de la inmediatez de las circunstancias. El "ante” al que nos referimos constituye un ángulo de pensamiento que articula planos especificables de conocimientos, de ahí que el acto de pensar consista en la capacidad para colocarse en el momento-secuencia que cumple la función de parámetro orientador para la construcción de conocimiento (Zemelman, 2011, p. 39).

Con este alumbramiento del mundo se está en condiciones para tomar una actitud y elegir que se quiere hacer, no habrá engaño, se conseguirán los resultados planeados. Esto es importante. Dejar en claro las condiciones de la actividad académica permite planear logros y objetivos alcanzables, de lo contrario la frustración y la queja se harán presentes. Eso es ubicarse dentro del mundo educativo, reconocer su lugar y el horizonte desde donde se partirá para llegar hacia el fin de educar, entonces se puede ver otros senderos por dónde ir, rodear, detenerse, o quizá abrir otros tiempos y espacio en los recorridos, proyectar y modificar circunstancias que pueden tener cabida en el proyecto educativa de la IES.

El docente tiene la posibilidad de darse cuenta que, dentro del salón de clases no hay rutina, es un momento de creación y potencialidades; si él las ha visto, tiene la tarea de enseñárselas al estudiante y compartirlas con sus pares; en eso consiste pensar-se: abrir los ojos y despertar de la ignorancia no solo intelectual, sino también social, económica, política, psicológica y afectiva.

\section{Conclusiones}

Indudablemente el contexto sociocultural y político del cual forma parte una persona puede condicionar a una forma de vida que quizá no guste tanto. Quizá estos contextos sean determinantes para muchos y se vea reflejado en su forma de actuar, sus comportamientos, valores, costumbres, etc., pero también pensar en un sujeto que no cambia es una posición muy determinista. Como sujetos históricos, sociales y políticos se tiene la posibilidad de generar cambios desde la individualidad y la colectividad.

$\mathrm{Al}$ ser seres sociales generamos relaciones con los otros y, por tanto, en el diálogo y la confrontación se pueden generar propuestas de cambios y transformaciones en las prácticas cotidianas. Recuperar lo historicidad del sujeto implica reconocerse en un espacio, tiempo, cultura que demanda la reflexividad y la toma de conciencia en el devenir de sus acciones, de sus experiencias y saberes. Posicionarse como un ser político permite confrontar las luchas de poder en la relación con los otros y darle un significado distinto al quehacer diario y, por ende, pensar la realidad de manera diferente, es decir, una realidad que pueda generar propuestas que incidan en la transformación social y cultural del sujeto. 
En este entendido, las prácticas educativas, se piensan, se estructuran y se ejecutan desde concepciones muy subjetivas o desde concepciones muy radicales; cualesquiera de estos dos posicionamientos traen consigo una forma muy particular de pensar el mundo. Es bien sabido que, en la educación, también existen las luchas de poder, entre la clase dominante y la dominada, unos que quieren imponer, controlar y legitimar sus intereses a través del currículum oculto y otros que intentan resistirse y desde sus propias prácticas generar una visión emancipadora de la educación.

La conformación de la capacidad crítica del docente desde su práctica puede ser posible siempre y cuando se reflexione sobre las contradicciones, en el salón de clases se pueden generar estrategias junto con las y los estudiantes que coadyuven al fortalecimiento de la reflexión, el análisis, la crítica y la acción. Conocer el posicionamiento del docente ante su práctica, la generación de preguntas, el respeto a las ideas, el diálogo, la socialización del conocimiento, ir más allá de lo que ofrece el texto, ubicar el contexto social, político, económico, pueden ser elementos que se deberían incorporar al debate educativo. Modificar la práctica y sobre todo develar sentidos y significados culturales no es tarea fácil, pero tampoco es algo que el docente no pueda reconocer.

Las posibilidades a las cuales se ve sujeto el y la docente y el alumnado para configurar una capacidad crítica ante sí mismo y con la sociedad abre horizontes en la conformación de un ciudadano autónomo. Las IES a pesar de que se les puede ver como espacios de lucha ideológica y saberes legitimados, también permiten la reflexión, la crítica y la emancipación del sujeto. Conformar al sujeto con una capacidad crítica no es tarea sencilla desde luego, pero la resistencia del sujeto a cuestionarse sobre su mundo y sus mundos, a explorar, a indagar otros terrenos desde la propia educación sin duda alguna puede ser un cultivo que lo aliente a mirarse como inconcluso, inacabado, deseoso de recuperar su memoria personal, social, histórica, con miras a reflexionar sobre su actuar interno y externo del mundo.

Si el personal docente es capaz de darse cuenta, concientizarse de el para qué de su ejercicio educativo, será mucho más fácil de contagiar a sus estudiantes a despertar también en ellos la capacidad crítica. Que el contenido organizado en los planes y programas de estudio se conviertan en pretextos para discernir de las prácticas sociales y culturales impuestas y se vuelvan armas ideológicas de un pensamiento emancipador y no reproductivo.

El currículum no determina al docente en su práctica, pero sí lo incita de manera consciente o inconsciente a generar prácticas legitimadas o de reproducción social o prácticas que puedan posibilitarle una reflexividad y conciencia histórica, social, y política, pero está en él, desde sus propios referentes ideológicos constituir o desarrollar una capacidad crítica que le permita diseñar o crear prácticas educativas diversas que sean catalizadores para la transformación individual y social.

La autonomía del docente en su práctica implica resistencia, así como también concientización, aprovechar el currículum formal puede ser una vía, hacerse de los saberes explícitos para posteriormente develarlos, analizarlos, criticarlos y una vez hecho esto, empezar a modificar su quehacer. Apelemos a aquellos docentes que encontramos en muchas aulas y que se han resistido y modificado su práctica ante un sistema dominante e impositivo.

Las IES tienen la obligación no solo de legitimar, reproducir saberes y conocimientos, sino también ser espacios de transformación, que en manos de docentes y estudiantes puedan ser elementales en la búsqueda de una sociedad más justa e igualitaria y menos alienante, pasiva y sumisa. El salón de clases puede convertirse en el único espacio donde docente y estudiante compartan experiencias de vida, sociales, educativas, y en el cual se aprendan a reconocer a sí mismos y ante los demás y un lugar que se convierta en un espacio de reflexión y crítica hacia consigo mismos y hacia el entorno sociocultural y político del cual forman parte. Todavía queda un largo camino que recorrer. 


\section{ReFERENCIAS}

Apple, M. (1990). Política, economia y poder en la Educación. México: Universitaria.

Bauman, Z. (2008). Los retos de la educación en la modernidad líquida. Barcelona: Gedisa.

Bauman, Z. (2009). Vida de consumo. México. Fondo de Cultura Económica.

Beck, U. (2002). La sociedad del riesgo global. España, Siglo XXI.

Betancourth, S. (2015). Desarrollo del pensamiento crítico en docentes universitarios. Una mirada cualitativa. Revista Virtual Universidad Católica del Norte, (44), 238-252. Recuperado de www.redalyc.org/ pdf/1942/194238608017.pdf

Brookfield, S. (1989). Developing Critical Thinkers. San Francisco: Jossey-Bass

De Alba, A. (1991). Curriculum: crisis, mito y perspectivas. México: UNAM-CESU

Ferry, G. (1990). El trayecto de la formación: Los enseñantes entre la teoria y la práctica. México: Paidós.

Freire, P. (1990). La naturaleza politica de la educación. Cultura, poder y liberación. Barcelona: Paidós.

Freire, P. (1997). Pedagogía de la autonomía. Saberes necesarios para la práctica educativa. México: Siglo XXI.

Freire, P. (2010). El grito manso. México: Siglo XXI Editores.

Giroux, H. (1992). Teoria y resistencia en educación: Una pedagogía para la oposición. México: Siglo XXI.

Glazman, R. (2009). Educación y conformación de una capacidad crítica. En A. De Alba y R. Glazman. ¿Qué dice la investigación educativa? México: COMIES.

Glazman, R. (2014). Capacidad critica. El dilema ético del docente que promueve la crítica y el diálogo. Recuperado de https://goo.gl/yYMGCW

León, F. (2014). Sobre el pensamiento reflexivo, también llamado pensamiento crítico. Propósitos y Representaciones, 2 (1), 161-214. Recuperado de https://dialnet.unirioja.es/descarga/articulo/5475194.pdf

Lipovestsky, G. (2003). La era del vacio. Barcelona: Anagrama

Lyotard, J. F. (1998). Lo inhumano. Charlas sobre el tiempo. Buenos Aires: Manantial.

McLaren, P. (1998). La vida en las escuelas: una introducción a la Pedagogía critica en los fundamentos de la educación. México: Editores Siglo XXI.

Pansza, M. (1997). Pedagogía y currículo. México: Gernika

Rojas, C. (2010). Filosofía de la Educación. De los griegos a la tardomodernidad. Medellín: Universidad de Antioquia.

Sacristán, G. (1998). El curriculum: una reflexión sobre la práctica. España: Morata

Sorbes, J. y Torres, N. (2013). ¿Cuáles son las concepciones de los docentes de ciencias en formación y en ejercicio sobre el pensamiento crítico? TED, (33), 61-85. Recuperado de www.scielo.org.co/pdf/ted/n33/n33a03.pdf

Villalobos, J. y Cabrera, C. M. (Enero-Junio, 2009). Los docentes y su necesidad de ejercer una práctica reflexiva. Revista de Teoria y Didáctica de las Ciencias Sociales, 14.

Zemelman, H. (2006). El conocimiento como desafí posible. México: Instituto Pensamiento y Cultura en América Latina, A. C.

Zemelman, H. (2011). Conocimiento y sujetos sociales. Contribuciones al estudio del presente. La Paz, Bolivia: Instituto Internacional de Integración del Convenio Andrés Bello.

\section{Notas}

[1] En este sentido entendemos el currículum como la síntesis de elementos culturales (conocimientos, valores, costumbres, creencias, hábitos) que conforman una propuesta político-educativa pensada e impulsada por diversos grupos y sectores sociales cuyos intereses son diversos y contradictorios, aunque algunos tiendan a ser dominantes o hegemónicos, y otros tiendan a oponerse y resistirse a tal dominación o hegemonía. (De Alba, 1991. p. 38).

[2] Cada uno de nosotros se encuentra inserto en una realidad que se asemeja, pero que no necesariamente es compartida, la concepción del mundo, de la historicidad del sujeto, para Freire (1997) es una posibilidad que permite que este sujeto 
le encuentre sentido y trascendencia a su vida. Si bien es cierto que la realidad se construye consigo mismo y con el otro, ambas se fusionan para generar una conciencia que le permita actuar de una manera determinada en su cotidianidad.

[3] A decir de Glazman (2009) "la capacidad crítica se ocuparía de las actitudes y valores desde las que un sujeto aborda el conocimiento para incorporarlo, integrarlo o debatirlo. Esto implica promover, en la escuela, procesos de valoración y pronunciamientos teniendo claro que la ideología, la idiosincrasia, la historia, en fin el imprinting de cada individuo sustentan los distintos marcos de valoración" (p. 242).

[4] A decir de Giroux (1992), "la ideología tiene que ser concebida como el origen y el efecto de prácticas sociales e institucionales que operan dentro de una sociedad caracterizada principalmente por relaciones de dominación -una sociedad en la cual hombres y mujeres básicamente no son libres en términos objetivos y subjetivos-. De ahí que recupere la interacción de ideología y experiencia individual situado en tres esferas específicas: de la inconsciencia y de la estructura de las necesidades, el ámbito del sentido común y de la conciencia crítica” (p. 187).

[5] En ese sentido, la ideología puede actuar como momento crítico en la producción de significados aclarando las reglas, suposiciones e intereses que estructuran no sólo el proceso de pensamiento sino también los objetos de análisis. La dimensión ideológica que subyace a toda reflexión crítica, que revela los valores históricos y sociales sedimentados que funcionan en la construcción del conocimiento, las relaciones sociales y de las prácticas materiales (Giroux, 1992, p. 196).

\section{BY-NC-ND}

